This is an electronic reprint of the original article. This reprint may differ from the original in pagination and typographic detail.

\author{
Author(s): Notko, Marianne; Jokinen, Kimmo; Kuronen, Marjo; Pirskanen, Henna; Malinen, Kaisa; \\ Harju-Veijola, Minna
}

Title: $\quad$ Encountering ethics in studying challenging family relations

Year: $\quad 2013$

Version:

Please cite the original version:

Notko, M., Jokinen, K., Kuronen, M., Pirskanen, H., Malinen, K., \& Harju-Veijola, M. (2013). Encountering ethics in studying challenging family relations. Families, Relationships and Societies, 2(3), 395-408. https://doi.org/10.1332/204674313X665085

All material supplied via JYX is protected by copyright and other intellectual property rights, and duplication or sale of all or part of any of the repository collections is not permitted, except that material may be duplicated by you for your research use or educational purposes in electronic or print form. You must obtain permission for any other use. Electronic or print copies may not be offered, whether for sale or otherwise to anyone who is not an authorised user. 
Article manuscript:

Encountering ethics in studying challenging family relations

Authors:

1. Marianne (Kristiina) Notko, PhD, Postdoctoral Researcher

Family Research Centre, University of Jyväskylä

P.O. Box 35, FI-40014 University of Jyväskylä, Finland

marianne.notko@jyu.fi

2. Kimmo (Juhani) Jokinen, PhD, Professor of Family Studies

Family Research Centre, University of Jyväskylä

P.O. Box 35, FI-40014 University of Jyväskylä, Finland

kimmo.j.jokinen@jyu.fi

3. Marjo (Leena Anneli) Kuronen, PhD, Adjunct Professor, Lecturer

Department of Social Sciences and Philosophy, University of Jyväskylä

P.O. Box 35, FI-40014 University of Jyväskylä, Finland

marjo.l.a.kuronen@jyu.fi

4. Henna (Kristiina) Pirskanen, PhD, Coordinator of the University of Lapland Graduate School, University of Lapland

Faculty of Social Sciences, University of Lapland

P.O. Box 122, FI-96101 Rovaniemi, Finland

henna.pirskanen@ulapland.fi 
5. Kaisa (Eveliina) Malinen, PhD, Postdoctoral Researcher

Family Research Centre, University of Jyväskylä

P.O. Box 35, FI-40014 University of Jyväskylä, Finland

kaisa.e.malinen@jyu.fi

6. Minna (Sisko Elina) Harju-Veijola, PhD Student

Family Research Centre, University of Jyväskylä

P.O. Box 35, FI-40014 University of Jyväskylä, Finland

minna.s.harju-veijola@student.jyu.fi

Correspondence concerning this article should be addressed to: Marianne Notko,

marianne.notko@jyu.fi, Family Research Centre, University of Jyväskylä, P.O. Box

35, FI-40014 University of Jyväskylä, Finland

Word count: 7745 including references 
ENCOUNTERING ETHICS IN STUDYING CHALLENGING FAMILY

RELATIONS

Abstract

This article focuses on ethical considerations in the study of challenging family relations. Our perspective derives from multidisciplinary family studies, including social sciences, psychology and educational science. Our concerns include why and how to apply a sensitive approach in studying challenging family relations, and what the ethical key issues are in studies of this kind. We examine questions of multiplicity in family relations, the particularity of vulnerable family relations and the roles of researchers and gatekeepers in the research process. The article is based on a research project where informants were both children and adults, and both qualitative and quantitative data was collected. We argue that doing ethically appropriate research requires much more than formal assessments or ethical board reviews. We claim that rigid ethical regulations may even prevent reaching hard-to-find families or impede the giving of a voice to those who would benefit most from being heard in family studies and in family politics.

Keywords: family relations, ethical issues, research practices, vulnerability 


\section{ENCOUNTERING ETHICS IN STUDYING CHALLENGING FAMILY}

\section{RELATIONS}

\section{Introduction}

The privacy of family life is highly valued in Western societies. There is much in family relations that offers a framework for everyday moral dialogue. For example, issues of the couple relationship and parent-child relationship, as well as those of personal space and intimacy are subjects of unending ethical debate and emotional evaluation, both at the societal and individual family level. It can reasonably be argued that our understanding of everyday moral dialogue and ethics is necessary to our understanding of family relations. Family research has recently become increasingly interested in the moral evaluations and negotiations that family members engage in (e.g. Carling et al., 2002). It is important to notice that the very word 'moral' does not in this context mean the same thing as moralistic (Morgan, 2002), although family issues could - and quite often do - also give rise to moralistic public debates (see e.g. Coltrane and Adams, 2003).

Like family life, family research is also closely linked to ethical considerations. Family matters, such as child birth, cohabitation, marriage, separation, divorce, sickness, domestic violence, sexual abuse and death, are sensitive areas of life. For family researchers, studying experiences that fall into these categories is a task replete with tensions. Because the family and family relations can be understood and seen as a private sphere of life, they may not easily be talked about or disclosed to outsiders. Family relations may be perceived as sacred and therefore not to be willingly 
profaned by family members. (Fontes, 2004; Smart, 2006.) Home is also seen as a private place where family members as insiders are able to maintain and protect their privacy and guard its boundaries against outsiders, including researchers (e.g. Allan, 1989). One can say that researchers interested in private, intimate spaces such as the home and family relations, are involving themselves in a sensitive research domain. This also means that scholars interested in family life need to broaden their understanding of the ethical aspects of their research and evaluate the effects of participation on the family as a whole as well as on individual family members - both participants and non-participants (Margolin et al., 2005).

In this article the focus is on the concrete ethical considerations that need to be taken into account when studying challenging family relations, especially when children are involved. Our ideas are based on a multidisciplinary research project on how children construct and maintain emotional security in multiple family relations. However, our concern is not ethical issues related to studying children alone; other important ethical questions and challenges are also present when studying family life and family relations. These ethical issues inevitably link with and influence the methodological possibilities and decisions of researchers in family studies.

Our background disciplines include sociology, social work, educational sciences and psychology. This multidisciplinarity offers us a unique opportunity not only to reflect variations in ethical, methodological and theoretical considerations between disciplines but also deal with a shared data set. Sociology and social work as disciplines offer us insights into the institutions and structures affecting family life and family relations, while we draw on psychology and education for perspectives on 
family life at the individual and interpersonal levels, and e.g. for conceptualisations on emotional security. In addition, social work and psychology, in particular, have dealt with ethical questions concerning family members in the context of social services, child protection and counselling, expertise in all of which is needed in our research. Methodologically speaking, combining multiple methods, some of which are used in some disciplines more than others, enables us to review the phenomenon of interest from various angles.

In the following, we highlight the most challenging and difficult ethical questions we have faced in the ethical evaluation of our project and during the data collection. Our understanding on research ethics conforms to both theory and everyday practices, including the ethics of family life, particularly in the area of research on sensitive topics. In the latter, particular attention has been paid to, among others, the vulnerability of and possible threats to participants. In addition, family life and relations have been conceptualised as an area of study in need of specific ethical considerations (Fontes, 2004; Lee and Renzetti, 1990; see also Hämäläinen et al., 2011; Lämsä et al., 2012). Our main questions concern why and how to apply a sensitive approach in studying family relations characterised by multiple negotiations, and what constitute the key ethical issues research on private life and close relations. We begin by introducing our project, the research setting and questions, and the data. Second, we introduce the so called moral or ethical turn in family studies by linking ethical issues to family life and to research on families and family relations. Third, we discuss the consideration we gave to ethical rules and the workings of the ethics review panels we acquainted ourselves with before we started collecting the data. We 
also go through some of the ethically challenging situations we encountered during the data collection process.

\section{Studying children with multiple family relations}

The material for this article on ethical considerations is based on a research project Children's emotional security in multiple family relations, funded by the Academy of Finland programme Health and welfare of children and young people (SKIDI-KIDS) in 2010-2013. Our research interest in this project lies in children living in complex and challenging family relations and the ways in which such children develop and maintain their emotional security in these relations and in their daily life. We share the views of the so called new childhood research according to which children are seen as agents constructing their own lives and therefore able to express their opinions, act in their families and other environments, and take part in creating and maintaining their own well-being (see e.g. Corsaro, 2005). We share the recognition of children as reflexive, competent social actors, which indicates the need for renewed scrutiny of the contribution children make within the different social arenas they occupy (Brannen et al., 2000). A voice will be given primarily to children, but also to their adult family members.

One of our main concepts is multiple family relations, which refers to a variety of family forms. Alongside nuclear families - biological parents with children - we have included reconstituted families, one-parent families, divorced families, and foster families. These family models display different relations, which vary in terms of their biological or social nature, length, intensity and the form of residence, for example 
whether the parents are living together or apart. A child may have relations in all of these contexts, for example a child living in a foster family and who visits the biological father’s new family.

To give a voice primarily to children who live in challenging family relations, we are focusing on three different, sometimes also intertwined, family situations. First, we are studying children who live in foster families; second, children who have experienced or witnessed physical or emotional violence or parental substance abuse, and third, children who have experienced the divorce or separation of their parents. All of these children are involved with appropriate institutions such as child protection or domestic violence-related NGOs. To add to this, we have also included two small elementary schools and their pupils from the fifth and sixth grades to obtain information from children living in so-called "ordinary” nuclear families. Therefore the schools were selected from elementary schools located in a residential suburb without any distinctive quality. At time of writing this article, we have collected data from altogether 60 children aged 11 to 13, and have just started to interview their parents.

We have followed the principles of mixed methods in our data collection. Our methods include thematic interviews, network maps, time lines and mobile diaries. $A$ mobile phone-based diary method has been utilised to gain insight into children's everyday family life and to capture children's emotions and daily activities and interactions (for the mobile diary method see Rönkä et al., 2010). Diary questions dealt with daily moods, social relations, and happy and unhappy moments during the day. The mobile diary comprised seven structured questions such as "Have you been 
in an irritable mood today?” ( 1 = “not at all”, 7 = “the whole day”) and three open questions, for example "Tell us one sad event that happened to you today? With who did you spend it?” The questions were sent to children as short text message once a day over a period of one week and children used their own mobile phones in answering the questions.

The same children have also been individually interviewed using thematic interviews, including questions concerning their family relations, emotionally significant family events and feelings of security and insecurity in the context of these relationships. At the start of the interviews we asked them to map their family on a network map. The purpose was, first, to gain insight into family memberships - who belonged to children's families and how close they were - and, second, to understand the ways children conceptualise their family relationships. Besides the family map we used the life course approach, a line of life in which children were asked to mark the most noteworthy turning points in their family life, whether these were positive or negative. (See e.g. Backett-Milburn et al., 2004; Brannen et al., 2000; Čermák, 2004; Roberts, 2004.) The advantages of using visual techniques like these when interviewing on sensitive topics include dissolving the tensions of the interview situation, breaking the ice and changing the power dynamics of the situation in the interviewee's favor. (Wilson et al., 2007; Parry et al., 1999.)

In the second stage of the research, we have started to interview adults children had mentioned as important to them during the data collection. These adults were mostly one of their biological or social parents, either resident or non-resident. With this method, we were able to get both adult and child perspectives on the same families 
and family relations. Quite often adults are asked issues about children because children are not considered reliable informants. This is not our aim; instead we expect to get multiple and possibly even contradictory perspectives on the same family relations.

This relates to our theoretical approach according to which families have multiple voices, a feature which may also change over time and space. For example, Zartler (2010, referring to Larson and Richards, 1994) writes that families are "the meeting ground of multiple realities”. However, reaching these multiple voices and realities also raised both methodological and ethical considerations. Studying several family members from the same families relates to the question of confidentiality (Margolin et al., 2005). During the research process participants may share information that is considered private and something not to be shared with another family member. In particular, parents and children may have different perspectives on what is too private to be shared. On the other hand, family members may be reluctant to talk about their negative - or contradictory - emotions towards other family members, especially if the situation causing tensions or contradictions is still on-going (Smart, 2007). The researcher juggling with the tensions and problems of contradictory family situations needs ethical understanding and skill (Pösö, 2008). As Jamieson (2011) points out, interpreting and representing the contested, complex and fluid realities of families and relationships is both a challenging and rewarding business. All in all, family researchers may be faced with several challenging issues in the data gathering process including sensitivity, emotions, contradictions and the need to intervene, as, for example, highlighted by Hämäläinen et al. (2011). 


\section{Family relations, emotions and ethical concerns}

One of the starting points in our research project is to locate emotions at the heart of family relations. Probably, there are only a few issues in the family context that have nothing to do with emotions. As Carol Smart (2007) says, family relationships are saturated with them so that they are almost a constituent art of family life itself. We experience ourselves as family members through memories, emotions, secrets, evaluations, and negotiations of relationality, connectedness and embeddedness, in which the significance of everyday ethical considerations is obvious. However, emotions have been rarely studied and theorised in family research. As Daly (2003) notes, "emotions have been overshadowed by the rationalisation of the family realm".

Emotions and ethical considerations, in turn, can be seen as involving an aspect of value. David Morgan (2011) states that to place value on something is also to express an emotional response to what is valued. This brings us closer to the question of ethics. Especially sensitive issues in family practices and relations, such as caring, sexuality and personal space, or, as is the case in our project, children's experiences in different kinds of family formations, break-ups and dark sides of family life, such as violence, are usually subjects of everyday ethical debates. Research on close, intimate relationships has to be attentive to the world of emotions and the ethics of everyday life. Lynn Jamieson, Roona Simpson and Ruth Lewis (2011a, 2011b) emphasise that family research is deeply embedded in relationships and intimate connections of different kinds. The level of researcher involvement in the relationships of the families researched is high. Family members are related to each other in varying ways, and researchers are related to their participants and to the private sphere of family life. 
However, research also involves relationships with colleagues, gatekeepers, such as ethics committees, and other academic actors. Multiple realities and differing perspectives co-exist within families and family research. Moreover, these relationships and perspectives usually involve different responsibilities, feelings, power relations, ethical challenges and other topics that need to be taken into consideration in the research process. The process itself may raise complex ethical dilemmas that sometimes can and sometimes cannot be predicted in advance. Therefore family researchers have highlighted the importance of reflecting on the research process and the ethical issues that emerge during it as an elementary part of the research process - and at every stage of the process. However, it is not easy to separate the everyday ethics in families from the ethical considerations in family research. In this article we are interested in both although we are not able to avoid the complexities to which these ethical considerations and a reflexive approach can give rise.

The recent research literature offers some good examples of the relations between ethics and family practices. The study Negotiating family responsibilities, by Janet Finch and Jennifer Mason, is often referred in this connection. Finch and Mason (1993) understand family relations and kinship as an arena of negotiations that concern various ideological and social practices and values. Obligations between family members are not self-evident but instead, are based on ethical considerations of who should do what and why, for example in terms of the provision of informal care for relatives. The facts that people are related and kinship is binding are central to understanding why they help each other. But in contemporary societies the constitution of the family and kinship is more flexible and challenging. As a 
consequence, the fulfilling of obligations requires negotiations in which the family members define and redefine who belongs to their family and evaluate whose needs are reasonable. To add to this, caring also involves negotiations with others and responsiveness to others. These are sensitive tasks, and careful ethical considerations are needed in fulfilling them. Finch and Mason conclude their study by saying that these moral dimensions of family responsibilities must be taken into account when doing research on family obligations and the relationships between family members.

Carol Smart and Bren Neale (1999) studied definitions of significant family relationships and the organisation of family life in the late modern world, in which family structures and family forms have become more diverse, due to divorce, remarriage and other transitions. They show that we cannot view divorce as a moment when morality and ethical considerations are abandoned. On the contrary, when parents think about how to organise care for their children after divorce or separation, they have to reflect upon the decisions they will take and weigh up the consequences of their actions. In intimate life, especially during transitions, new kind of moral thinking is needed. Changing family arrangements and obligations must be negotiated with sensitivity.

As said before, our interest lies in children's experiences of family relations that can be challenging and not easy to handle, for example situations and relations shadowed with negative emotions or experiences, such as violence, abandonment, neglect, and drug abuse. Separation, divorce, a father's or mother's re-partnering, living in a foster family, and fear of an adult family member create a new space for the negotiation of family boundaries with inclusions and exclusions. The construction of the new family 
raises the question of how to develop emotional bonds with new adults and perhaps new (step)siblings as well as grandparents, and how to keep in touch with physically more distant family members who are not living in the same household. Principles of love, care, respect and support - all deeply embedded in ethical evaluations - are the elements most often used by children to build a 'proper' family for themselves. (Smart, Neale and Wade, 2001.) Based on the versatile study by Brannen et al. (2000) on children's accounts of their family relations, children emerge as active coparticipants in care and as co-constructors of family life. Like adults, children make sense of the rules which guide caring behaviour and negotiate these in relation to particular contexts and situations. Furthermore, they make sense of their experiences of family life and change.

The examples mentioned above of studies on family relations highlight the importance and centrality of everyday practical ethics. Owing to its importance Morgan (2011) speaks about an ethical turn that has taken place in family studies and claims that this turn has contributed greatly to our understanding of the family in late modern society. Thus there are reasons for our linking the family and ethical practices. We would like to add that the linkage between ethics and family studies is at least as important.

\section{Ethical regulation and gatekeepers}

Several researchers have recently paid attention to the growing formal ethical regulation of social scientific research, and its implications, in particular, for research in the fields of the family and children, often understood as sensitive issues and/or 
vulnerable groups (e.g., Gabb, 2010; Lagström et al., 2010; Melrose, 2011). Some researchers argue that this might hinder or even prevent the study of many important topics. Others find formal regulation, such as advance approval by an ethical committee, important but emphasise that this will not by itself guarantee an ethical research process, unless researchers are sensitive and reflective to ethical issues at all stages of the research process (e.g., Gorin et al., 2008).

Our research was granted ethical approval by the University of Jyväskylä ethics committee. In addition, we decided to approach children and their families via several service agencies, such as Save the Children (children living in foster homes) and a national NGO, helping victims of domestic violence (children who have experienced violence in their family relations). To avoid harm and distress, we wanted to be sure that all the children were already receiving professional help and also had access to their help system during the research process. The organisations we cooperated with were willing to help us, but they also acted as gatekeepers. The organisations selected potential informants from their clients. They used ethically based criteria such as the family situation being currently relatively stable; for example, actions relating to foster care had been taken some time ago. The problem for us with this manner of proceeding was that we were unable to make direct contact with potential informants and explain them personally our starting points and the purpose of our study. However, we are unable to say whether this did or did not limit participation. Working with the NGOs in the data collection also involved a lot of time and effort. It has been argued that managing the consent process can be particularly complicated in research in which gatekeepers or third parties are involved. From a practical point 
of view the presence of gatekeepers in the research project complicates the recruiting process. Before family members can give their consent to participate, gatekeepers must be persuaded to take part in the study. Gatekeepers, by definition, control, but may also enable, access to certain groups of people. Using gatekeeping agencies such as health and social care agencies may be the only way to reach people who are in some ways vulnerable. (Iphofen, 2009; Liamputtong, 2007.)

As discussed by Melanie Mauthner and colleagues (2002), gatekeepers are often used in gaining access to persons who may be less powerful. In addition, Mauthner et al. stress the importance of giving careful consideration to who is giving consent and to what. Powerlessness can also mean being less able to resist 'voluntary' participation, for example if the data collection is organised through an agency in which the participants are clients. In our study, we also used gatekeepers, and for strongly ethically driven reasons. The only exception was our school data. First, we chose the schools and classes and asked children to participate, and it was only through the actual data collection that we learned whether an interviewee child had problems at home or not. If we felt there was cause for anxiety, we contacted the school welfare officer.

By and large, our principle was that we could not include children with known adverse childhood experiences unless we knew that they were already involved with a helping agency. Therefore we started collecting the data by contacting NGOs and relying on their help to find informants. However, contrary to the findings of Mauthner et al. (2002), in our study the participants chosen and suggested by the gatekeeping organisations seemed to very aware of their rights to decline participation. 
For example, biological parents could refuse not only their own but also their children's participation. A social worker, with whom we cooperated with, relayed the answer of one mother: “I don’t give permission for that. When my children were taken into custody, I was against it. I don’t like them being interviewed either.” In this sense it is necessary to rethink also 'the power of the powerless'. It is possible that decisions of this kind (e.g., for the biological parents of foster care children) are among the last ones they have the power to make - and therefore they are closely guarded.

\section{Challenges faced in data collection}

The data collection process with families, especially the kind of family relations we were interested in, may come up against various dilemmas. Researchers should pay attention to practical matters such as whether to interview individuals in their own homes where the possible presence of other family members might risk and challenge confidentiality and anonymity. When dealing with sensitive issues such as domestic violence, substance abuse or child maltreatment researchers may face situations in which they are ethically and/or officially obliged to intervene (Gorin et al., 2008; Margolin et al., 2005). According to the World Health Organization (WHO) ethical and safety recommendations for domestic violence research, the safety of respondents and the research team is paramount, and should infuse all project decisions. Also the study design must include a number of actions aimed at reducing any possible distress caused to the participants by the research (WHO, 2001; Ellsberg and Heise, 2002). These recommendations apply to all studies conducted on challenging family relations. 
However, according to Gabb (2010), there is a significant difference between the risk of causing distress and risk of causing harm. Harm is usually the term referred in the biomedical sciences and in clinical trials. Hollway and Jefferson (2000) claim that while talking about emotionally important matters can be highly distressing for some individuals, it is quite different from being harmed. In our study we find this distinction useful, but we are also alert to the possibility of overlap between distress and harm. For example, one of our interviewees talked about his home and parents; when in turn his mother was interviewed, she asked what her son had said in his interview. Obviously, the interviewer did not reveal what the child had said, referring to it simply as "nothing special”. The mother appeared content with the answer. However, we cannot be sure what happened at home after the interviews. In this sense, ethical questions are very practical questions of participants' safety and wellbeing.

Thus, ethically informed research should seek to prevent harm and risks to the participants. Such research should be beneficial and non-maleficent, do good, and actively promote the welfare of the participants, or at least minimise any possible harm to them. The benefits of participating in research might include, for example, personal learning and growth for the participants, having their voices heard, or personal and social empowerment. (Peled and Leichtenritt, 2002; Iphofen, 2009.) In our research project we aimed at increasing benefits of this kind, for example in choosing our study themes and framing our interview and diary questions. The rights and well-being of participants is a central ethical concern; for example, when they are very young, their vulnerability merits special attention (Iphofen 2009). 
Despite our careful, ethically driven concrete preparations, we encountered several problems. One of these concerned children living in foster care and their biological parents. In these families consent to participate was required from the children themselves as well as from both their biological and foster parents. Obtaining consent from the biological parents was anything but straightforward. Some of the biological parents refused to allow their child to participate in the study, even though the foster parents had agreed. In one occasion, the biological parents, their child and the foster mother agreed to participate. However, the foster father declined. His reason for this was that the child had just moved to a new home, and it was not yet appropriate for him to take part in a study of this kind. Despite our disappointment at losing potential research material this occasion awoke us to the fact that ethically driven decisions are justified differently by different family members.

Foster care family relations per se manifest various forms of embedded multiplicity, emotions and contradictions. The division of care, responsibilities, attachment and loyalties are concretely visible in terms of who is allowed to talk about the families and persons involved. In addition, this effects the possibilities of gathering quantitatively sufficient data. As Margolin and colleagues (2005) state, family researchers need to be sensitive to families’ power relations both across and within generations when recruiting participants for their studies. As our experience shows, when studying children in foster families these complex power relations might even seriously influence on the accomplishment of the whole research project. In our data collection process, the interview situations were also challenging from the ethical viewpoint. Researchers dealing with sensitive family matters need awareness not only of the norm-based ethics of their research practices, such as informed consent, 
confidentiality and anonymity, but also of the situational ethics. In interview situations, the researcher can encounter ethical questions that need an immediate reaction according to one’s best judgment. (Heath et al., 2009; Josselson, 2007.) It is inevitable that even if the research group modifies some of the ethical rules beforehand, individual researchers will still have to puzzle out situations as they arise in the research interview.

Especially with children or other vulnerable groups, it is important to know from where to obtain further support if something serious is revealed. Physical violence in the family in the past, parents' alcohol or substance abuse problems and issues related to living in a foster family, for example potential disagreements about child care between the biological and social parents, were some of the topics that the researchers needed to be prepared to face in their interviews with children with contradictory and problematic family relations. When interviewing children on such difficult topics, we sometimes also experienced the gatekeeper NGOs involved as our "safety nets". We were able to leave the field with somewhat lighter hearts than we would probably have done otherwise due to our knowledge that the NGO’s social workers and therapists would be available to help if the child was upset or emotional afterwards. Of course it was also our responsibility to talk with each child at the end of the interview and ask how s/he had experienced the interview.

In our interviews the most challenging moments were related to the threat experienced by the children in their family relations and to the mood experienced by the children in the moment of interview. We shall give a concrete example of each of these two moments, as they may be of interest to other researchers in this field. First, we 
describe a case of threat and second, a case of emotion. In the threat case, the child reported that he had been threatened by his parents and had received corporal punishment. We had prepared some rules should such situations arise. If the child appeared to be in physical danger we were obliged to inform the authorities, in this case, the school social worker. According to the basic principles of minimising harm and maximising benefits (e.g., Ellsberg and Heise, 2002), this should be done in the interests of the child. However, it was not that simple a task. The relationships between the researcher and the child became contradictory. The researcher had to break the ethical principle of confidentiality by informing a third party of what the child had told the researcher. Sarah Nelson (2011) considers similar questions in her accounts of children revealing adverse experiences in survey studies. She makes the important point that troubled children may write in the confused hope that despite ‘confidentiality’ someone will do something. She also refers to the suggestion by child protection specialists that, at the minimum, information sheets with the contact details of helpful agencies should always be provided in sensitive research with children. Nevertheless, no definitive answer to the 'confidentiality-versusintervention’ dilemmas is likely to be found.

The second case concerns how the researcher deals with interviewees' emotions (see also Gabb, 2010, Gorin at al., 2008). The moods of children in interviews can also be considered a challenging factor. In one particular interview, a girl cried throughout. What she said in the interview was not at all alarming or distracting, but the way she acted worried the interviewer considerably. Another girl started to cry when she was asked about her future hopes. She said that all of her friends were travelling abroad 
with their families, but her one-parent family couldn’t afford to do the same, because her mother had been unemployed for a long time.

The ethics in such situations are linked to both the ethical principles involved in studying sensitive areas and to the ethics of family life. First, one of the core principles in this kind of research is ensuring the willingness of the participant. The informant cannot be forced to take part in research and he or she has to have a possibility to discontinue at any phase of the study. In these two cases the researchers had to decide whether to stop or to continue the interview. The researchers discussed this with the girls, telling them that they can stop the interview with no negative consequences to themselves. The girls expressed the wish to continue and the interviews went ahead as planned. However, this raises questions of free will, choice and having a full understanding of the purposes of the research and the rights of the informant. Could it be that the girls did not dare to tell the researchers that they wanted to stop? Can the power relationship between the adult interviewer and the child participant affect the decisions a child makes in an interview?

Second, the situation of the girl weeping when asked about her hopes for the future illuminates the ethics of family life in a deep sense. Family members, including children, can be acutely aware of what is meant by a "good" or "proper" family life. Therefore the fact that her family situation, with unemployed parent, means that she cannot enjoy the same future prospects as her peers made the girl miserable when asked about it. At the same time, it highlights how emotion-laden and filled with moral tensions family life can be. 
It is also crucial to think through ethical issues specific with regard to the mobile phone diary method. On account of the distance between the researcher and the respondent, mobile phone diaries are closer to surveys than interviews. On the other hand, the method is more interactive than the survey, despite the lack of any possibility for giving immediate responses. We also discussed the privacy issues which might occur if the child leaves the answers on his or her mobile phone and some other family member reads them. For this reason, we guided the respondents to delete sent messages. In addition, we pondered the possibilities of misunderstanding the answers and our limitations in figuring out technical solutions and their effects on the data. It is necessary to take into account the fact that different methods produce different kinds of knowledge, which we as researchers, closely combining well thought out ethical, methodological and theoretical positions, must then interpret.

When gathering data from children the researcher needs thoroughly to think through various ethical issues, not only before embarking on the study, but especially also during it. Being a researcher is often a lonely occupation and a researcher therefore has to have a possibility to share experiences with others in the same situation. Sharing challenging moments will help to shape a set of consensual ethical practices that can be applied in the study of family relations (see also Gorin et al., 2008). As Lisa Aronson Fontes (1998) points out, all researchers are morally obligated to think deeply about ethical issues, to discuss these issues with others and to keep their moral compasses delicately tuned.

\section{Conclusions and discussion}


As Jacqui Gabb (2010) states, in empirical qualitative studies of family life, the researcher inevitably becomes embedded in the personal worlds of those being researched. To add to this, we find all family research, whether quantitative or qualitative, heavily intertwined with issues of privacy and vulnerability. However, this fact should not mean over-cautiousness in a sense that we should decline to study family relations that are contested or to ask questions that might reveal something we did not expect or want to hear. Such an approach would leave many valuable themes unexplored and many essential questions unanswered. Our study also showed that ethical considerations involved many more people than just those we set out to interview or asked to answer mobile phone diary questions. Multiple family relations mean various individuals with different relations to each other and multiple processes that have to be gone through if the study is to be accomplished. The researchers' task is to puzzle out these connections. In the cases of child informants we were also dependent on gatekeepers, such as the child protection organisations or domestic violence-related NGOs through which we recruited the participants. All this forms a unique research setting with multiple actors, and including researchers, informants and their families, and the organisations involved.

One of our core findings concerns the possibility of limitations in our data and skewed results. We claim that applying rigid ethical regulations may yield data and participants that are highly selected, and, as happened in our study, fewer interviews and less data that was planned. For example, several domestic violence studies indicate that only a small proportion of victims seek help (Bacchus et al., 2003; Garcia-Moreno, 2002; Krug et al., 2002; Peckover, 2003). This means that studying victims of domestic violence who are already in helping systems only manage to 
reach the tip of the iceberg. However, exploring 'tips' may be the only possibility. As much as we have struggled with our data collection processes, we have been reluctant to yield in many questions, especially those concerning children. Still, we argue that small samples can also produce important knowledge on rarely studied issues. It is also useful to combine several data types and take advantage of the principles of mixed methods (e.g., Mason, 2006; Gabb, 2010).

We have argued that strictly following the formal ethical rules set by particular agencies may prevent access to the kinds of family life that most merit scrutiny and in the worst case also limit the amount and weaken the quality of the data. This does not mean ignoring ethical rules but rethinking and moulding them to fit life that has been beyond the reach of research. In family research, ethical rules can and must be enhanced across the whole complexity, and even messiness of family life as lived. It should be also critically evaluated what principles of action are to be followed if the study reveals adverse experiences, such as substance abuse or domestic violence in the family. This is crucial, especially in cases involving children and the provisions of child protection legislation, but also in the case of the adults living in conflicting situations. Studying challenging family relations often means managing ambivalence. Therefore we suggest that new critical perspectives are needed that will enable responsible yet open-minded approaches to family studies and ethics. 
References

Allan, G. (1989) ‘Insiders and outsiders. Boundaries around the home’ in G. Allan and G. Crow (eds) Home and family. Creating the domestic sphere. Basingstoke: Macmillan.

Bacchus L., Mezey G. and Bewley S. (2003) 'Experiences of seeking help from health professionals in a sample of women who experienced domestic violence', Health and Social Care in the Community, 11 (1): 10-18.

Backett-Milburn, K. and Harden J. (2004) 'How children and their families construct and negotiate risk, safety and danger', Childhood, 11 (4): 429-447.

Brannen, J., Heptinstall, E. and K. Bhopal (2000) Connecting children. Care and family life in later childhood, London: Routledge Falmer.

Carling, A., Duncan, S. and Edwards, R. (eds) (2002) Analysing families. Morality and rationality in policy and practice, London: Routledge.

Čermák, I. (2004) ““Genres” of life-stories’ in D. Robinson, C. Horrocks, N. Kelly and B. Roberts (eds) Narrative, memory and identity: theoretical and methodological issues, Huddersfield: University of Huddersfield.

Coltrane, S. and Adams, M. (2003) 'The social construction of the divorce "problem”: Morality, child victims, and the politics of gender', Family Relations, 52 (4): 363372.

Corsaro, W. (2005) The sociology of childhood. 2nd edition, Thousand Oaks: Pine Forge Press.

Daly, K. (2003). 'Family theory versus the theories families live by', Journal of Marriage and Family, 65 (4): 771-784.

Ellsberg, M. and Heise, L. (2002) 'Bearing witness: ethics in domestic violence research', The Lancet, 359 (9317): 1599-604.

Finch, J. and Mason, J. (1993) Negotiating family responsibilies. London: Routledge.

Fontes, L. A. (1998) 'Ethics in family violence research: cross-cultural issues', Family Relations, 47 (1): 53-61.

Fontes, L. A. (2004) 'Ethics in violence against women research. The sensitive, the dangerous and the overlooked', Ethics \& Behavior, 14 (2): 141-174. 
Gabb, J. (2010) 'Home truths: ethical issues in family research'. Qualitative Research 10 (4): 461-478.

Garcia-Moreno C. (2002) 'Dilemmas and opportunities for an appropriate healthservice response to violence against women', The Lancet, 9316 (359): 15091514.

Gorin, S., Hooper, C.-A. and Cabral, C. (2008) 'Ethical challenges in conducting research with hard to reach families', Child Abuse Review, 17 (4): 275-287.

Heath, S., Brooks, R., Cleaver, E. and Ireland, E. (2009) Researching young people's lives, London: Sage.

Hollway, W. and Jefferson, T. (2000) Doing qualitative research differently: free association, narrative and the interview method. London: Sage.

Hämäläinen, K., Pirskanen, H. and Rautio, S. (2011) 'Studying sensitive and contradictory family situations: considerations from three family studies', Journal of Comparative Social Work, 4 (1), http://jcsw.no/local/media/jcsw/docs/jcsw_issue_2011_1_4_article.pdf

Iphofen, R. (2009) Ethical decision-making in social research. A practical guide, Houndmills, Basingstoke and Hampshire: Palgrave Macmillan.

Jamieson L. (2011) 'Interpreting and representing families and relationships' in L. Jamieson, R. Simpson and R. Lewis (eds) Reseraching families and relationships. Reflections on Process. Houndmills: Palgrave Macmillan, 122149.

Jamieson, L., Simpson, R. and Lewis, R. (2011a) 'Introduction’ in L. Jamieson, R. Simpson and R. Lewis (eds) Reseraching families and relationships. Reflections on Process. Houndmills: Palgrave Macmillan, 1-18.

Jamieson, L., Simpson, R. and Lewis, R. (2011b) ‘Conclusion’ in L. Jamieson, R. Simpson and R. Lewis (eds) Reseraching families and relationships. Reflections on Process. Houndmills: Palgrave Macmillan, 178-188.

Josselson, R. (2007) 'The ethical attitude in narrative research. Principles and practicalities' in D. Jean Clandinin (ed.) Handbook of narrative inquiry. Mapping a methodology, Thousand Oaks, London and New Delhi: Sage Publications.

Krug E.G., Dahlberg L.L., Mercy J.A., Zwi A.B. and Lozano R. (2002) World report on violence and health, World Health Organization, Geneva. 
Lagström, H., Pösö, T., Rutanen, N. and Vehkalahti, K. (2010) (eds) Lasten ja nuorten tutkimuksen etiikka [Ethics in studying children and adolescents], Helsinki: Nuorisotutkimusseura.

Lee, R.M. and Renzetti, C. (1990) The problems of researching sensitive topics. An overview and introduction. American Behavioral Scientist, 33, 510-528.

Liamputtong, P. (2007) Researching the vulnerable. A guide to sensitive research method, Thousand Oaks, CA: Sage.

Lämsä, T., Rönkä A., Poikonen P.-L., and Malinen, K. The child diary as a research tool. Early Child Development and Care, 182 (3-4): 469-486.

Margolin, G., Chien, D., Duman, S. E, Fauchier, A., Gordis, E. B., Oliver, P. H., Ramos, M. C. and Vickerman, K. A. (2005) 'Ethical issues in couple and family research', Journal of Family Psychology, 19 (1): 157-167.

Mason, J. (2006) 'Mixing methods in a qualitatively driven way', Qualitative Research (1), 9-25.

Mauthner, M., Birch, M., Jessop, J. and Miller, T. (2002) 'Consenting to what? Issues of access, gate-keeping and 'informed' consent' in M. Mauthner, M. Birch, J. Jessop and T. Miller (eds) Ethics in qualitative research, 54-67 (online version).

Melrose, M. (2011) 'Regulating social research: Exploring the implications of extending ethical review procedures in social research', Sociological Research Online, 16 (2):14, http://www.socresonline.org.uk/16/2/14.html

Morgan, D. (2002) 'Sociological perspectives on the family' in A. Carling, S. Duncan and R. Edwards (eds) Analyzing families. Morality and rationality in policy and practice, London: Routledge.

Morgan, D. (2011) Rethinking family practices. Houndmills, Basingstoke and Hampshire: Palgrave Macmillan.

Nelson, Sarah (2011) 'See no evil, hear no evil: Do children in distress take second place?' in L. Jamieson, R. Simpson and R. Lewis (eds) Researching families and relationships. Reflections on Process. Houndmills: Palgrave Macmillan, $67-70$.

Parry, O., Thomson, C. and Fowkes, G. (1999) 'Life course data collection: Qualitative interviewing using the life grid', Sociological Research Online, 4 (2), http://www.socresonline.org.uk/4/2/parry.html 
Peckover S. (2003) 'I could have just done with a little more help’: an analysis of women's help-seeking from health visitors in the context of domestic violence, Health and Social Care in Community, 11 (3): 275-282.

Peled, E. and Leichtentritt, R. (2002) The ethics of qualitative social work research, Qualitative Social Work, 1 (2): 145-169.

Pösö, T. (2008) 'Kiistanalaiset perhesuhteet ja tutkimisen moraali' [Contradictory family relations and the morals of research] in E. Sevón and M. Notko (eds) Perhesuhteet puntarissa [Studying family relations], Palmenia-series 43. Helsinki: Gaudeamus.

Roberts, B. (2004) 'Life lines, life connections and biographical traces/forms' in D. Robinson, C. Horrocks, N. Kelly and B. Roberts (eds) Narrative, memory and identity: Theoretical and methodological issues, Huddersfield: University of Huddersfield.

Rönkä, A., Malinen, K., Kinnunen, U., Tolvanen, A., and Lämsä, T. (2010) 'Capturing daily family dynamics via text messages: Development of the mobile diary’, Community, Work \& Family, 13 (1): 5-21.

Smart, C. (2006) 'Children’s narratives of post-divorce family life: from individual experience to an ethical disposition', The Sociological Review, 54 (1): 155-170.

Smart, C. (2007) Personal life. New directions in sociological thinking, Polity Press.

Smart, C., Neale, B. and Wade, A. (2001) The changing experience of childhood: families and divorce. Cambridge: Polity.

Smart, C. and Neale, B. (1999) (eds) Family fragments? Cambridge: Polity Press.

Wilson, S., Cunningham-Burley S., Bancroft, A., Backett-Milburn, K. and Masters, H. (2007) 'Young people, biographical narratives and the life grid: young people's accounts of parental substance use', Qualitative Research, 7 (1): 135151.

WHO (2001) Putting women first: ethical and safety recommendations for research on domestic violence against women. Department of gender and women's health family and community health. World Health Organization Geneva, Switzerland.

Zartler, U. (2010) 'Multiple perspectives in qualitative family research: Crafting and conducting research projects’, Family Science, 1 (3-4): 173-182. 